\title{
Undrained stability of active and passive trapdoors
}

Jim Shiau PhD

Senior Lecturer, School of Civil Engineering and Surveying, University of Southern Queensland, Toowoomba, Australia (corresponding author: jim.shiau@usq.edu.au)
Mohammad Mirza Hassan MEng

Postgraduate student, School of Civil Engineering and Surveying, University of Southern Queensland, Toowoomba, Australia

The recent growth in the number of sinkhole occurrences due to human activities has highlighted the need for better understanding and prediction of the problem. This paper investigates the use of Broms and Bennermark's original stability number for trapdoor problems in cohesive soil. The shear-strength-reduction method built in a finite-difference method software program (FLAC) is used to obtain the factor of safety (FOS) under different combinations of pressures for collapse and blowout. Unlike previous research on the use of critical pressure ratios, the FOS results are now functions of the original stability number and depth ratio. The obtained numerical results are compared and validated by using rigorous upper- and lower-bound finite-element limit analysis, as well as other existing solutions available in the literature. Surface failure extents are also examined in the paper. The dimensionless ratios employed in this study are useful for preparing design charts with a broad range of trapdoor geometries and soil parameters.

\section{Notation}

C soil cover

D tunnel diameter

E extent of the failure surface

$H \quad$ depth from the ground surface to the trapdoor opening

$N \quad$ 'designed' stability number

$N_{\text {c }} \quad$ critical stability number

$r^{2} \quad$ correlation coefficient

$S_{\mathrm{u}} \quad$ undrained shear strength of soil

W trapdoor width

$\gamma \quad$ soil unit weight

$\sigma_{\mathrm{s}} \quad$ surcharge pressure

$\sigma_{\mathrm{t}} \quad$ support pressure

$\Phi \quad$ internal friction angle of soil

\section{Introduction}

Sinkholes present environmental risk through subsidence or sudden ground collapse, leading to loss of life and infrastructure. The recent growth in the number of sinkhole occurrences due to human activities, such as urbanisation, mining and agricultural development, has highlighted the need for better understanding and prediction of the problem (Drumm et al., 2009).

Sowers (1996) outlined the sub-profile of karst soil and described the process of forming a sinkhole. It was suggested that in limestone areas, the gradual erosion of rock at a depth caused by the passing of underground water leads to subsidence of overburden deposited soil, resulting in a saucer-shaped depression. Field investigation studies (Newton, 1976; Sowers, 1996) also suggested that the underground voids, created either naturally or by humans, initiated in cracks between the underground rocks. As indicated by Tharp (2003), the initial size of the cavity does not reflect the actual size of the trapdoor at collapse because the size of the initial cavity will grow further due to internal erosion and will create a reverse-funnel shape.
A considerable number of studies have been published on the stability of trapdoors. A study was initiated by Terzaghi (1936), who experimentally investigated the effect of distributed stress in sand. The study categorised the failure as either an active or a passive mode and described active failure as occuring due to overburden pressure and passive failure occurring as an uplifting force such as an anchor.

Through laboratory experiments and field data collection, Broms and Bennermark (1967) stated that the support pressure required to maintain the stability of an opening on a vertical wall should equate to overburden pressures (surcharge and self-weight) and the undrained shear strength of the soil multiplied by a 'factor'. The stability number $(N)$ was therefore defined in the following equation

1. $N=\frac{\sigma_{\mathrm{s}}+\gamma H-\sigma_{\mathrm{t}}}{S_{\mathrm{u}}}$

where $\sigma_{\mathrm{s}}$ is the surface surcharge pressure; $\sigma_{\mathrm{t}}$ is the support pressure; $H$ is the depth of the opening; $\gamma$ represents the soil unit weight; and $S_{\mathrm{u}}$ is the undrained shear strength of the soil. Broms and Bennermark (1967) also concluded that the opening would be unstable when the overburden pressure $\left(\sigma_{\mathrm{s}}+\gamma H\right)$ is six times greater than the undrained shear strength of the soil.

One of the most influential studies of underground stability comes from Davis et al. (1980), who used an analytical approach to study tunnel heading stability. Davis et al. (1980) used the limit analysis theorem to determine upper-bound and lower-bound solutions to the problem. In their approach, unlike the original Broms and Bennermark (1967) stability number approach, the problem was approached differently by using a critical pressure ratio $\left(\sigma_{\mathrm{s}}-\sigma_{\mathrm{t}}\right) / S_{\mathrm{u}}$, which is a function of the strength ratio $\left(\gamma D / S_{\mathrm{u}}\right)$ and depth ratio $(H / W)$, as indicated in Equation 2. Numerous 
studies have since been performed using this approach (Augarde et al., 2003; Drumm et al., 2009).

2.

$$
N=\frac{\sigma_{\mathrm{s}}-\sigma_{\mathrm{t}}}{S_{\mathrm{u}}}=f\left(\frac{\gamma D}{S_{\mathrm{u}}}, \frac{C}{D}\right)
$$

Koutsabeloulis and Griffiths (1989) used the displacement finiteelement method to investigate soil displacement in active and passive modes of the trapdoor problem. Martin (2009) introduced a new slipline solution for a shallow trapdoor. Craig (1990) utilised a centrifuge model to investigate the critical stability of a circular cavity. Using the centrifugal approach, many experimental investigations of trapdoor stability have been carried out by researchers, such as Abdulla and Goodings (1996) and Jacobsz (2016). Recently, Keawsawasvong and Ukritchon (2017) studied active trapdoor problems with a linear increase in undrained shear strength with depth using finite-element limit analysis (FELA).

Although extensive research has been carried out on the stability of trapdoors in the past, most of the studies have predominately focused on the use of the critical pressure ratio $\left(\left(\sigma_{\mathrm{s}}-\sigma_{\mathrm{t}}\right) / S_{\mathrm{u}}\right)$. Very few studies have used the original stability number approach (Broms and Bennermark, 1967) to study soil stability and further explore the relationship between the stability number and the factor of safety (FOS). In this paper, the shear-strength-reduction method (SSRM) is used with the finite-difference method (FDM) to obtain the FOS for a wide range of stability numbers $(N)$ and depth ratios $(H / W)$. This study also investigates the extent of sinkhole collapse on the ground surface. The results are validated by using FELA and other previous published studies. These FOS results are used to produce comprehensive design charts for the problem of trapdoor stability.

\section{Statement of the problem and modelling technique}

The development of cover-collapse sinkholes is a complex procedure due to the continuous expansion of the cavity size over the time. To simplify the problem, it is assumed that the cavity is in the critical stage where the failure is imminent. Figure 1 shows the problem definition of an idealised horizontal trapdoor underlying a homogeneous layer of cohesive soil. The undrained soil is modelled as uniform Mohr-Coulomb material with a zero soil internal friction angle $(\Phi=0) . S_{\mathrm{u}}$ is the undrained shear strength, and $\gamma$ is the soil unit weight. The trapdoor opening width is $W$, and the depth from the surface to the trapdoor opening is notated as $H$.

Note that the combination of surcharge pressure $\left(\sigma_{\mathrm{s}}\right)$, overburden pressure $(\gamma H)$ and support pressure $\left(\sigma_{t}\right)$ can produce failure in either a collapse or a blowout. For undrained clay without volume loss during plastic shearing, stability results are independent of loading directions, and Broms and Bennermark's original undrained stability number is a suitable design parameter (Shiau and Al-Asadi, 2018). For drained soils, the original stability number is not applicable.
A broad range of stability numbers $(N=-15-15)$ and depth ratios $(H / W=1-10)$ have been chosen to cover all possible investigations of collapse and blowout. Note that the actual values of $\sigma_{\mathrm{s}}, \sigma_{\mathrm{t}}, \gamma, S_{\mathrm{u}}, H$, and $W$ used in the analyses are insignificant and are not to be reported here due to the nature of the dimensionless definition. The SSRM is adopted to solve the FOS, which is a function of the stability number $N$ and the depth ratio $H / W$, as shown in the following equation

$$
\text { 3. } \mathrm{FOS}=f\left(N, \frac{H}{W}\right)
$$

Due to the lack of previous literature on implementing the FOS approach as well as correlating the stability number $N$ to the FOS, it is important to use two techniques for the comparison of results. For this reason, both the FDM and FELA were used to analyse the problem in this paper.

The FDM is one of the oldest techniques used in numerical studies and is a powerful method for analysing complex geotechnical stability problems involving non-linear solutions (Itasca, 2003). A typical grid for simulating the trapdoor stability problem in the FDM is shown in Figure 2. To improve the computational efficiency, a symmetrical condition is considered. This symmetrical condition is particularly important for deep cases that normally require more central processing unit time. An effective domain should be such that it is large enough to present the entire velocity field. Both the left and the right boundaries of the mesh were fixed in the $x$-direction, allowing the soil to move in a vertical direction. The lower boundary of the mesh was restrained in both the $x$ - and $y$-directions except where the trapdoor opening is positioned. The trapdoor opening was not restrained so the soil body can freely move downwards into the cavity. A Fish script was developed to assist in auto mesh generation and problem solving of the trapdoor problem using SSRM (Shiau and Sams, 2019; Shiau et al., 2018). The Fish development was a

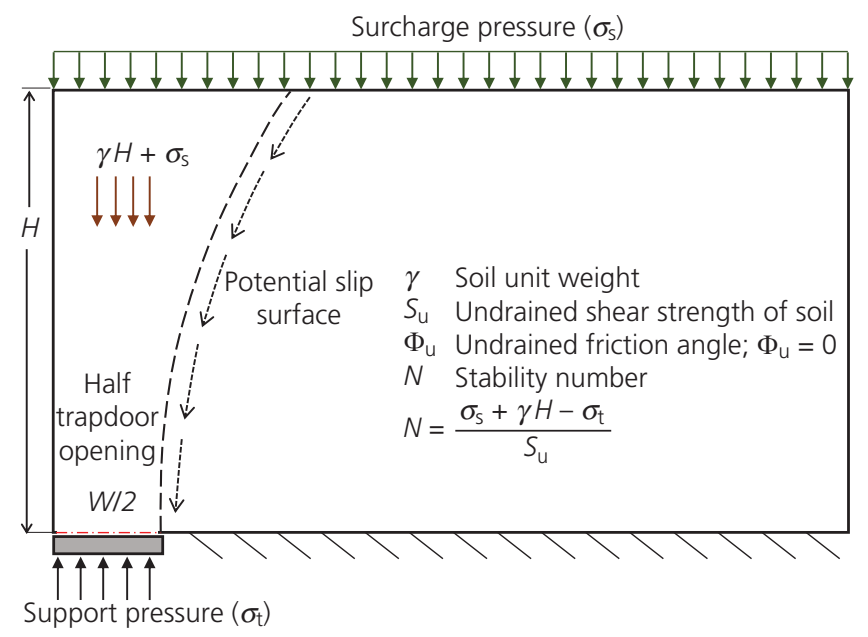

Figure 1. Problem definition 
Surcharge pressure $\left(\sigma_{\mathrm{s}}\right)$

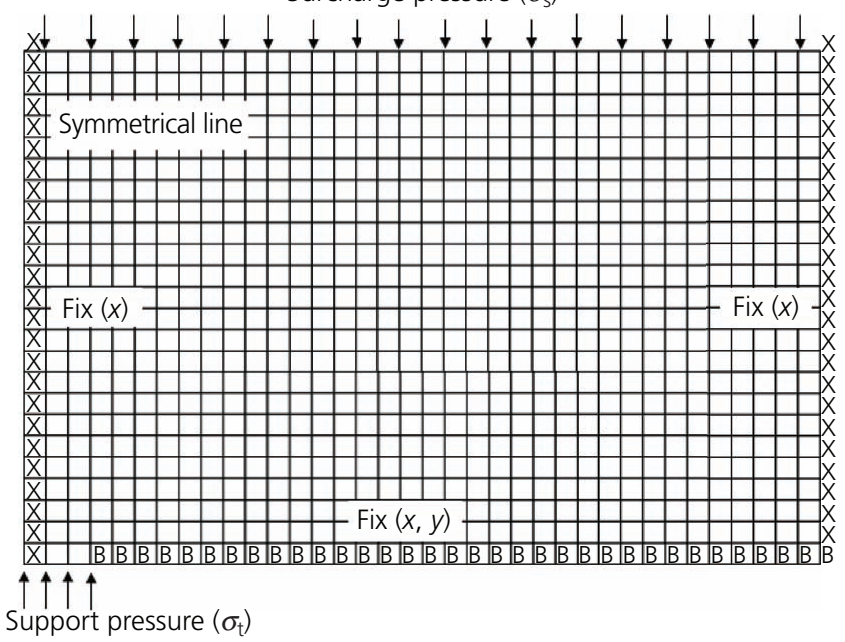

Figure 2. A typical FDM mesh used for the problem

particularly important tool in this study, as it allows parametric study to be conducted efficiently.

The numerical process of the FELA and SSRM is based on the limit theorems of classical plasticity, which were described by Lyamin and Sloan (2002a, 2002b) and Sloan (2013). The details of the formulation will not be repeated here. It is worth noting that the new technique utilises the finite-element discretisation to deal with complicated geometry and loading conditions and the plastic bounding theorems to bracket the true limit load using

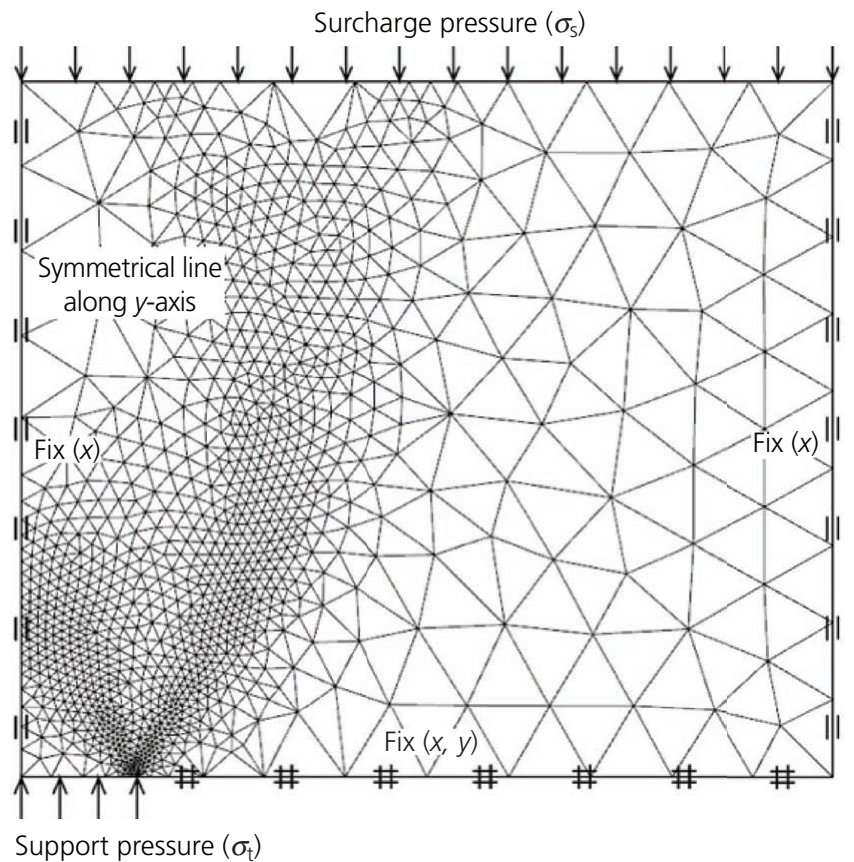

Figure 3. A typical FELA adaptive mesh used for the problem upper- and lower-bound solutions. Figure 3 shows the mesh used in the paper. The domain sizes of the models were carefully chosen by observing the non-zero velocity fields, so as to minimise boundary effects. Note that the symmetrical faces are fixed only in the normal direction (i.e. $x$-direction) to allow vertical movement, so as the outer face boundary. Similar to the FDM mesh, the lower face is restrained in the $x$ - and $y$-directions and the top face is free to displace in all directions. The solutions are then triggered by involving the shear-strength-reduction technique stated in the paper by Krabbenhoft and Lyamin (2015).

The SSRM was utilised as early as 1975 by Zienkiewicz et al. (1975) and many other researchers to investigate various geotechnical engineering problems (Griffiths and Lane, 1999; Krabbenhoft and Lyamin, 2015; Matsui and San, 1992; Michalowski, 2002; Ugai and Leshchinsky, 1995; Yang and Drumm, 2002). Although the SSRM provides a straightforward solution to many geotechnical problems, such as slopes and retaining walls, this method has seldom been used in the analysis of underground stability problems (Shiau et al., 2017, 2018). In this study, the SSRM and FOS approach is adopted to analyse the stability of the trapdoor in collapse and blowout conditions. A total of 690 trapdoor cases are studied using the FDM, upperbound FELA (FELA UB) and lower-bound FELA (FELA LB). Numerical results of the extensive investigation are presented in the form of design charts and equations.

\section{Results and discussions}

Comprehensive findings of this study are presented in Tables 1-3 for a broad range of stability numbers $(N=-15-15)$ and depth ratios $(H / W=1-10)$. Using the data in the tables, Figure 4 plots the FOS results of collapse and blowout from the analyses of lower bound, upper bound and finite differences for the depth ratio of $H / W=3$. The results show that the curves are in hyperbolic form where FOS and $N$ are the vertical and horizontal asymptotes, respectively. The general equation of the curve is presented as follows

\section{4. $N_{\mathrm{c}}=\mathrm{FOS} \times N$}

Equation 4 suggests that for a given depth ratio $(H / W=3)$, any combination of FOS and $N$ on the curve yields a unique value. This unique value is the critical stability number $\left(N_{\mathrm{c}}\right)$, which corresponds to an FOS of 1 . By drawing an FOS $=1$ horizontal line in Figure 4, the two intersection points give an $N_{\mathrm{C}}$ value of 4.925 for the collapse and -4.930 for the blowout.

When the supporting pressure ratio (SPR, $\left.\sigma_{\mathrm{t}} / S_{\mathrm{u}}\right)$ is greater than the overburden pressure ratio (OPR $\left.\left(\left(\sigma_{\mathrm{s}}+\gamma H\right) / S_{\mathrm{u}}\right)\right)$, the negative value of $N$ represents a blowout movement. Contrary to this, a positive value of $N$ indicates that the soil moves in the collapse condition. This occurs when the overburden pressure ratio $\left.\left(\left(\sigma_{\mathrm{s}}+\gamma H\right) / S_{\mathrm{u}}\right)\right)$ is greater than the supporting pressure ratio $\left(\sigma_{\mathrm{t}} / S_{\mathrm{u}}\right)$. As $N$ further increases, an incipient collapse is reached where FOS $=1$ and the corresponding $N$ is the critical $N_{\mathrm{c}}$. When the supporting pressure 
Table 1. FOS for various $N$ and $H / W$ values (FDM)

\begin{tabular}{|c|c|c|c|c|c|c|c|c|c|c|}
\hline \multirow{2}{*}{$N$} & \multicolumn{10}{|c|}{$H / W$} \\
\hline & 1 & 2 & 3 & 4 & 5 & 6 & 7 & 8 & 9 & 10 \\
\hline-15.00 & $0 \cdot 14$ & 0.26 & 0.33 & 0.38 & 0.42 & 0.44 & 0.47 & 0.49 & 0.51 & 0.53 \\
\hline$-12 \cdot 50$ & $0 \cdot 17$ & 0.31 & 0.39 & 0.45 & 0.50 & 0.53 & 0.56 & 0.59 & 0.62 & 0.63 \\
\hline$-10 \cdot 00$ & 0.22 & 0.39 & 0.49 & 0.56 & 0.62 & 0.67 & 0.71 & 0.74 & 0.77 & 0.79 \\
\hline$-7 \cdot 50$ & 0.29 & 0.52 & 0.66 & 0.76 & 0.83 & 0.89 & 0.94 & 0.99 & 1.02 & 1.06 \\
\hline$-5 \cdot 00$ & 0.43 & 0.78 & 0.99 & $1 \cdot 13$ & 1.24 & 1.33 & 1.41 & 1.49 & 1.53 & 1.59 \\
\hline-3.00 & 0.72 & $1 \cdot 30$ & 1.65 & 1.89 & 2.08 & $2 \cdot 23$ & 2.35 & 2.46 & 2.56 & 2.65 \\
\hline$-2 \cdot 00$ & 1.08 & 1.95 & 2.47 & $2 \cdot 83$ & $3 \cdot 11$ & $3 \cdot 34$ & 3.53 & 3.70 & 3.83 & 3.98 \\
\hline$-1 \cdot 00$ & $2 \cdot 16$ & 3.90 & 4.94 & $5 \cdot 67$ & $6 \cdot 24$ & $6 \cdot 70$ & 7.09 & $7 \cdot 42$ & $7 \cdot 67$ & 7.98 \\
\hline-0.75 & $2 \cdot 88$ & $5 \cdot 20$ & 6.59 & 7.57 & $8 \cdot 32$ & 8.94 & $9 \cdot 46$ & 9.90 & $10 \cdot 24$ & $10 \cdot 66$ \\
\hline-0.50 & $4 \cdot 32$ & $7 \cdot 80$ & 9.89 & $11 \cdot 35$ & $12 \cdot 49$ & $13 \cdot 40$ & $14 \cdot 17$ & 14.83 & $15 \cdot 42$ & 15.95 \\
\hline-0.25 & 8.64 & $15 \cdot 60$ & 19.77 & $22 \cdot 74$ & 25.04 & $26 \cdot 93$ & $28 \cdot 52$ & 29.91 & $31 \cdot 16$ & 31.90 \\
\hline 0.00 & Infinity & Infinity & Infinity & Infinity & Infinity & Infinity & Infinity & Infinity & Infinity & Infinity \\
\hline 0.25 & 8.63 & $15 \cdot 59$ & $19 \cdot 74$ & $22 \cdot 65$ & 24.92 & $26 \cdot 73$ & 28.26 & $29 \cdot 58$ & $30 \cdot 90$ & $31 \cdot 50$ \\
\hline 0.50 & $4 \cdot 31$ & 7.79 & $9 \cdot 86$ & $11 \cdot 32$ & $12 \cdot 43$ & $13 \cdot 34$ & $14 \cdot 10$ & 14.75 & $15 \cdot 38$ & 15.95 \\
\hline 0.75 & $2 \cdot 88$ & $5 \cdot 19$ & $6 \cdot 57$ & $7 \cdot 54$ & $8 \cdot 29$ & 8.89 & $9 \cdot 39$ & 9.83 & $10 \cdot 23$ & $10 \cdot 58$ \\
\hline 1.00 & $2 \cdot 16$ & 3.89 & 4.93 & $5 \cdot 65$ & $6 \cdot 21$ & $6 \cdot 66$ & 7.04 & $7 \cdot 37$ & $7 \cdot 66$ & $7 \cdot 91$ \\
\hline $2 \cdot 00$ & 1.08 & 1.95 & $2 \cdot 46$ & $2 \cdot 82$ & $3 \cdot 10$ & 3.33 & 3.52 & 3.68 & $3 \cdot 83$ & 3.95 \\
\hline 3.00 & 0.72 & $1 \cdot 30$ & 1.64 & 1.88 & 2.07 & $2 \cdot 22$ & $2 \cdot 34$ & $2 \cdot 45$ & 2.55 & $2 \cdot 62$ \\
\hline 5.00 & 0.43 & 0.78 & 0.99 & $1 \cdot 13$ & $1 \cdot 24$ & 1.33 & 1.40 & 1.47 & 1.53 & $1 \cdot 58$ \\
\hline $7 \cdot 50$ & 0.29 & 0.52 & 0.66 & 0.75 & 0.83 & 0.89 & 0.94 & 0.98 & 1.02 & 1.05 \\
\hline $10 \cdot 00$ & 0.22 & 0.39 & 0.49 & 0.56 & 0.62 & 0.67 & $0 \cdot 71$ & 0.74 & 0.76 & 0.79 \\
\hline $12 \cdot 50$ & 0.17 & $0 \cdot 31$ & 0.39 & 0.45 & 0.50 & 0.53 & 0.56 & 0.59 & 0.61 & 0.63 \\
\hline 15.00 & $0 \cdot 14$ & 0.26 & 0.33 & 0.38 & 0.41 & 0.44 & 0.47 & 0.49 & 0.51 & 0.53 \\
\hline
\end{tabular}

ratio $\left(\sigma_{\mathrm{t}} / S_{\mathrm{u}}\right)$ is equal to the overburden pressure ratio $\left(\left(\sigma_{\mathrm{s}}+\gamma H\right) /\right.$ $\left.S_{\mathrm{u}}\right)$ ), $N$ is equal to zero and FOS is at a maximum (infinite) where a 'stressless' scenario exists on the asymptote line.
Broms and Bennermark's original Equation 1 can be rearranged into a form that is more amenable to analysis, as shown in the following equation

Table 2. FOS for various $N$ and $H / W$ values (FELA UB)

\begin{tabular}{|c|c|c|c|c|c|c|c|c|c|c|}
\hline \multirow{2}{*}{$N$} & \multicolumn{10}{|c|}{$H / W$} \\
\hline & 1 & 2 & 3 & 4 & 5 & 6 & 7 & 8 & 9 & 10 \\
\hline$-15 \cdot 00$ & 0.13 & 0.25 & $0 \cdot 32$ & 0.37 & 0.41 & 0.44 & 0.46 & 0.48 & 0.50 & 0.52 \\
\hline$-12 \cdot 50$ & 0.16 & 0.30 & 0.38 & 0.44 & 0.49 & 0.52 & 0.55 & 0.58 & 0.60 & 0.62 \\
\hline$-10 \cdot 00$ & 0.20 & 0.37 & 0.48 & 0.55 & 0.61 & 0.65 & 0.69 & 0.73 & 0.75 & 0.78 \\
\hline$-7 \cdot 50$ & 0.26 & 0.50 & 0.64 & 0.74 & 0.81 & 0.87 & 0.92 & 0.97 & 1.01 & 1.04 \\
\hline-5.00 & 0.40 & 0.74 & 0.96 & $1 \cdot 10$ & $1 \cdot 22$ & $1 \cdot 31$ & $1 \cdot 38$ & 1.45 & $1 \cdot 51$ & $1 \cdot 56$ \\
\hline$-3 \cdot 00$ & 0.66 & $1 \cdot 24$ & $1 \cdot 59$ & $1 \cdot 84$ & 2.03 & $2 \cdot 18$ & $2 \cdot 31$ & $2 \cdot 42$ & $2 \cdot 51$ & $2 \cdot 60$ \\
\hline-2.00 & 0.99 & $1 \cdot 85$ & $2 \cdot 38$ & $2 \cdot 76$ & $3 \cdot 04$ & $3 \cdot 27$ & $3 \cdot 46$ & $3 \cdot 62$ & $3 \cdot 78$ & $3 \cdot 90$ \\
\hline-1.00 & 1.98 & $3 \cdot 70$ & $4 \cdot 77$ & $5 \cdot 51$ & $6 \cdot 11$ & $6 \cdot 53$ & 6.93 & $7 \cdot 24$ & $7 \cdot 55$ & $7 \cdot 80$ \\
\hline-0.75 & $2 \cdot 64$ & 4.95 & $6 \cdot 34$ & $7 \cdot 36$ & $8 \cdot 11$ & $8 \cdot 72$ & $9 \cdot 22$ & $9 \cdot 66$ & $10 \cdot 06$ & $10 \cdot 40$ \\
\hline-0.50 & $3 \cdot 96$ & $7 \cdot 39$ & $9 \cdot 53$ & 11.03 & $12 \cdot 21$ & 13.07 & $13 \cdot 85$ & $14 \cdot 50$ & $15 \cdot 11$ & $15 \cdot 60$ \\
\hline-0.25 & $7 \cdot 92$ & $14 \cdot 79$ & $19 \cdot 06$ & 22.05 & $24 \cdot 30$ & $26 \cdot 13$ & $27 \cdot 71$ & 28.99 & $30 \cdot 22$ & $31 \cdot 20$ \\
\hline 0.00 & Infinity & Infinity & Infinity & Infinity & Infinity & Infinity & Infinity & Infinity & Infinity & Infinity \\
\hline 0.25 & $7 \cdot 92$ & $14 \cdot 79$ & $19 \cdot 06$ & 22.05 & $24 \cdot 32$ & $26 \cdot 13$ & $27 \cdot 71$ & 28.99 & $30 \cdot 22$ & $31 \cdot 20$ \\
\hline 0.50 & 3.96 & $7 \cdot 42$ & $9 \cdot 53$ & 11.03 & $12 \cdot 16$ & 13.07 & $13 \cdot 85$ & $14 \cdot 50$ & $15 \cdot 11$ & $15 \cdot 60$ \\
\hline 0.75 & $2 \cdot 64$ & 4.95 & $6 \cdot 34$ & $7 \cdot 36$ & $8 \cdot 11$ & 8.72 & $9 \cdot 22$ & 9.67 & $10 \cdot 06$ & $10 \cdot 40$ \\
\hline 1.00 & 1.98 & $3 \cdot 70$ & $4 \cdot 77$ & $5 \cdot 51$ & 6.08 & $6 \cdot 53$ & 6.93 & $7 \cdot 25$ & $7 \cdot 55$ & $7 \cdot 80$ \\
\hline $2 \cdot 00$ & 0.99 & $1 \cdot 85$ & $2 \cdot 38$ & $2 \cdot 76$ & $3 \cdot 04$ & $3 \cdot 27$ & $3 \cdot 46$ & $3 \cdot 62$ & $3 \cdot 78$ & $3 \cdot 90$ \\
\hline $3 \cdot 00$ & 0.66 & $1 \cdot 24$ & $1 \cdot 59$ & $1 \cdot 84$ & 2.03 & $2 \cdot 18$ & $2 \cdot 31$ & $2 \cdot 42$ & $2 \cdot 51$ & $2 \cdot 60$ \\
\hline $5 \cdot 00$ & 0.40 & 0.74 & 0.96 & $1 \cdot 10$ & $1 \cdot 22$ & $1 \cdot 31$ & $1 \cdot 38$ & 1.45 & $1 \cdot 51$ & $1 \cdot 56$ \\
\hline $7 \cdot 50$ & 0.26 & 0.50 & 0.64 & 0.74 & 0.81 & 0.87 & 0.92 & 0.97 & 1.01 & 1.04 \\
\hline $10 \cdot 00$ & 0.20 & 0.37 & 0.48 & 0.74 & 0.61 & 0.65 & 0.69 & 0.73 & 0.75 & 0.78 \\
\hline $12 \cdot 50$ & 0.16 & 0.30 & $0 \cdot 38$ & 0.44 & 0.49 & 0.52 & 0.55 & 0.58 & 0.60 & 0.63 \\
\hline $15 \cdot 00$ & 0.13 & 0.25 & $0 \cdot 37$ & 0.37 & 0.41 & 0.44 & 0.46 & 0.48 & 0.50 & 0.52 \\
\hline
\end{tabular}


Table 3. FOS for various $N$ and $H / W$ values (FELA LB)

\begin{tabular}{|c|c|c|c|c|c|c|c|c|c|c|}
\hline \multirow{2}{*}{$N$} & \multicolumn{10}{|c|}{$H / W$} \\
\hline & 1 & 2 & 3 & 4 & 5 & 6 & 7 & 8 & 9 & 10 \\
\hline$-15 \cdot 00$ & 0.13 & 0.24 & 0.31 & 0.36 & 0.39 & 0.42 & 0.45 & 0.47 & 0.49 & 0.50 \\
\hline$-12 \cdot 50$ & $0 \cdot 16$ & 0.29 & 0.37 & 0.43 & 0.47 & 0.51 & 0.54 & 0.56 & 0.58 & 0.60 \\
\hline$-10 \cdot 00$ & 0.20 & 0.36 & 0.46 & 0.54 & 0.59 & 0.64 & 0.67 & 0.70 & 0.73 & 0.75 \\
\hline$-7 \cdot 50$ & 0.26 & 0.48 & 0.61 & 0.72 & 0.79 & 0.85 & 0.90 & 0.94 & 0.97 & 0.75 \\
\hline-5.00 & 0.39 & 0.72 & 0.93 & 1.08 & $1 \cdot 18$ & $1 \cdot 27$ & $1 \cdot 34$ & $1 \cdot 40$ & 1.46 & $1 \cdot 51$ \\
\hline-3.00 & 0.65 & $1 \cdot 20$ & $1 \cdot 54$ & 1.78 & 1.97 & $2 \cdot 12$ & $2 \cdot 24$ & $2 \cdot 35$ & $2 \cdot 43$ & $2 \cdot 51$ \\
\hline$-2 \cdot 00$ & 0.97 & 1.79 & $2 \cdot 32$ & $2 \cdot 68$ & 2.95 & $3 \cdot 18$ & $3 \cdot 37$ & $3 \cdot 52$ & $3 \cdot 65$ & $3 \cdot 79$ \\
\hline-1.00 & 1.94 & $3 \cdot 58$ & $4 \cdot 65$ & $5 \cdot 36$ & $5 \cdot 92$ & $6 \cdot 34$ & $6 \cdot 74$ & 7.03 & $7 \cdot 30$ & $7 \cdot 57$ \\
\hline-0.75 & $2 \cdot 59$ & $4 \cdot 79$ & $6 \cdot 20$ & $7 \cdot 17$ & $7 \cdot 90$ & $8 \cdot 46$ & 8.95 & $9 \cdot 39$ & $9 \cdot 76$ & 10.03 \\
\hline-0.50 & $3 \cdot 89$ & $7 \cdot 21$ & $9 \cdot 28$ & $10 \cdot 73$ & $11 \cdot 77$ & $12 \cdot 72$ & $13 \cdot 49$ & 14.05 & $14 \cdot 60$ & $15 \cdot 10$ \\
\hline-0.25 & $7 \cdot 72$ & $14 \cdot 41$ & 18.59 & $21 \cdot 45$ & $23 \cdot 54$ & $25 \cdot 44$ & 26.97 & $28 \cdot 10$ & $29 \cdot 21$ & $30 \cdot 10$ \\
\hline 0.00 & Infinity & Infinity & Infinity & Infinity & Infinity & Infinity & Infinity & Infinity & Infinity & Infinity \\
\hline 0.25 & $7 \cdot 78$ & $14 \cdot 32$ & $18 \cdot 53$ & $21 \cdot 47$ & $23 \cdot 61$ & $25 \cdot 44$ & $26 \cdot 95$ & $28 \cdot 10$ & $29 \cdot 21$ & $30 \cdot 29$ \\
\hline 0.50 & $3 \cdot 86$ & $7 \cdot 21$ & $9 \cdot 21$ & $10 \cdot 73$ & $11 \cdot 80$ & $12 \cdot 72$ & $13 \cdot 48$ & 14.05 & $14 \cdot 60$ & $15 \cdot 15$ \\
\hline 0.75 & $2 \cdot 59$ & $4 \cdot 76$ & $6 \cdot 20$ & $7 \cdot 15$ & $7 \cdot 87$ & 8.46 & 8.98 & $9 \cdot 39$ & $9 \cdot 78$ & $10 \cdot 10$ \\
\hline 1.00 & 1.95 & $3 \cdot 58$ & $4 \cdot 65$ & $5 \cdot 37$ & $5 \cdot 90$ & $6 \cdot 34$ & $6 \cdot 74$ & 7.03 & $7 \cdot 30$ & $7 \cdot 57$ \\
\hline $2 \cdot 00$ & 0.97 & $1 \cdot 80$ & $2 \cdot 32$ & $2 \cdot 68$ & 2.97 & $3 \cdot 18$ & $3 \cdot 37$ & $3 \cdot 51$ & $3 \cdot 65$ & 3.76 \\
\hline $3 \cdot 00$ & 0.65 & $1 \cdot 20$ & $1 \cdot 54$ & 1.79 & 1.98 & $2 \cdot 12$ & $2 \cdot 24$ & $2 \cdot 35$ & $2 \cdot 43$ & $2 \cdot 51$ \\
\hline $5 \cdot 00$ & 0.39 & 0.72 & 0.93 & 1.07 & $1 \cdot 18$ & $1 \cdot 27$ & $1 \cdot 35$ & $1 \cdot 41$ & $1 \cdot 46$ & $1 \cdot 51$ \\
\hline $7 \cdot 50$ & 0.26 & 0.48 & 0.62 & 0.72 & 0.79 & 0.85 & 0.90 & 0.94 & 0.97 & 1.01 \\
\hline $10 \cdot 00$ & 0.20 & 0.36 & 0.46 & 0.54 & 0.59 & 0.64 & 0.67 & 0.70 & 0.73 & 0.75 \\
\hline $12 \cdot 50$ & $0 \cdot 16$ & 0.29 & 0.37 & 0.43 & 0.47 & 0.51 & 0.54 & 0.56 & 0.58 & 0.60 \\
\hline $15 \cdot 00$ & 0.13 & 0.24 & 0.31 & 0.36 & 0.40 & 0.42 & 0.45 & 0.47 & 0.49 & 0.50 \\
\hline
\end{tabular}

5. $\sigma_{\mathrm{t}}=\sigma_{\mathrm{s}}+\gamma H-\left(N_{\mathrm{c}} \times S_{\mathrm{u}}\right)$

Using Equation 5, a critical supporting pressure $\sigma_{\mathrm{t}}($ when $\mathrm{FOS}=1)$ can be determined as long as $N_{\mathrm{c}}$ is known. Note that there is only one unique $N_{\mathrm{c}}( \pm)$ for a particular depth ratio and $N_{\mathrm{c}}$ is a function of

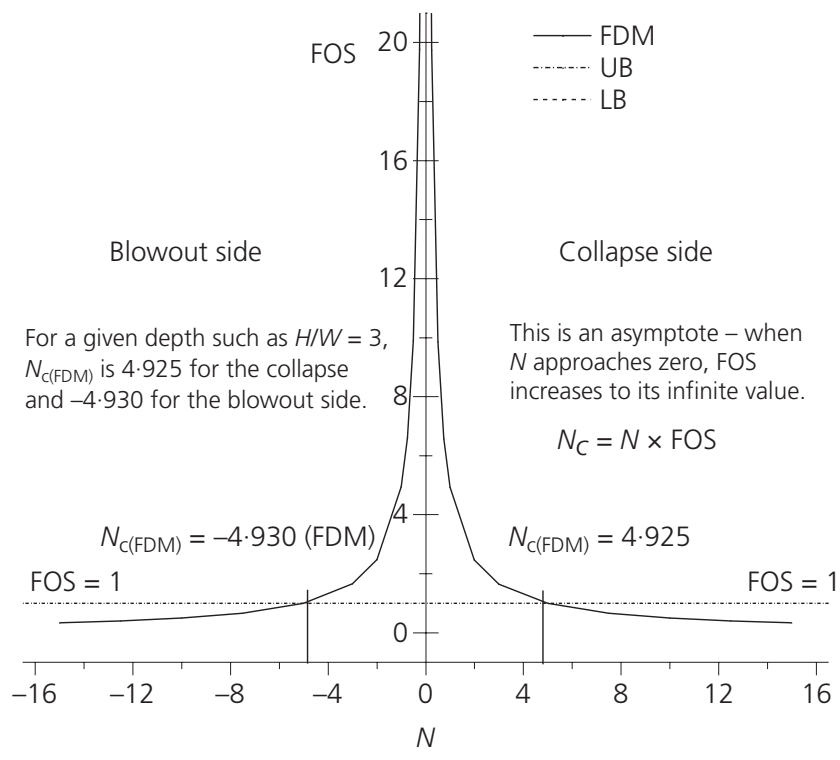

Figure 4. FOS plotted against $N(U B, L B$ and FDM) for a depth ratio of $H / W=3$ the depth ratio $H / W$ regardless of the undrained shear strength of the soil. It is therefore important to study the effect of $H / W$ on the critical stability number $N_{\mathrm{c}}$. Figure 5 shows such a relationship between $N_{\mathrm{c}}$ and $H / W$. Note that the critical stability number $\left(N_{\mathrm{c}}\right)$ increases nonlinearly as $H / W$ increases, and the gradient of the curve decreases for large values of $N_{\mathrm{c}}$. The area bounded by the collapse and the blowout curves represents the safe zone where FOS $>1$. As the stability number $(N)$ approaches zero $(\mathrm{OPR}=\mathrm{SPR})$, the FOS becomes infinite. Also, see the asymptote in Figure 4.

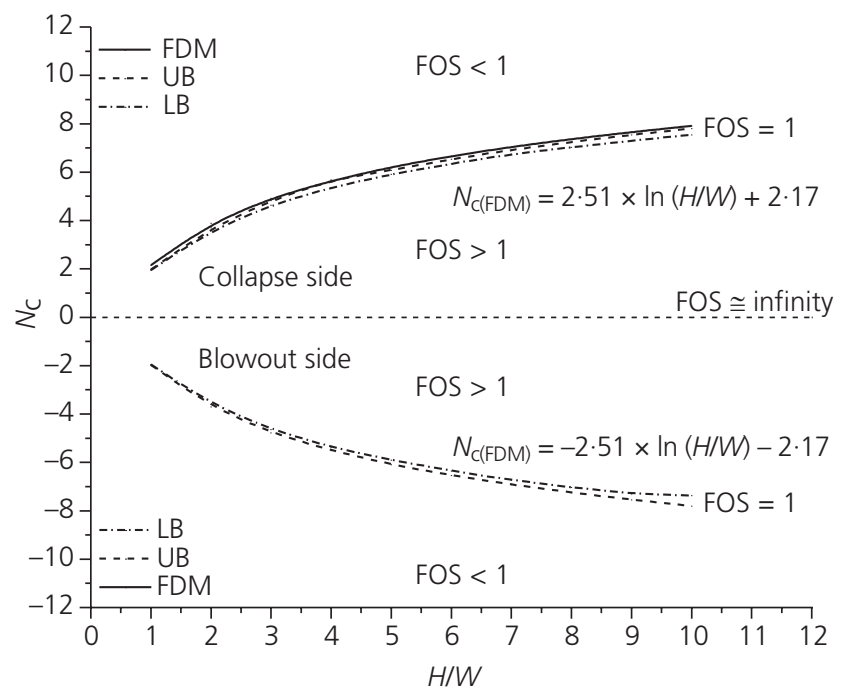

Figure 5. $N_{c}$ plotted against H/W (FDM, FELA UB and FELA LB) 
Note that the critical stability number $\left(N_{\mathrm{c}}\right)$ represents the 'design' $N$ value when $\mathrm{FOS}=1$. This is the failure envelope for $\mathrm{FOS}=1$. Also, note that FOS $>1$ when a design $N$ value is located within the failure envelope and FOS $<1$ when a design $N$ value is located outside the failure envelope.

The finite-difference results of $N_{\mathrm{c}}$ were chosen for the regression analysis. These are presented in Equations 6 and 7 for collapse and blowout, respectively, with a correlation coefficient $r^{2}=$ 0.998 .

6.

$$
N_{\mathrm{c}(\mathrm{FDM})}=2 \cdot 51 \times \ln \left(\frac{H}{W}\right)+2 \cdot 17
$$

7. $N_{\mathrm{c}(\mathrm{FDM})}=-2 \cdot 51 \times \ln \left(\frac{H}{W}\right)-2 \cdot 17$

Using Equations 1 and 4, the FOS can be determined with the following equation

8.

$$
\mathrm{FOS}=\frac{N_{\mathrm{c}}}{N}=\frac{N_{\mathrm{c}} \times S_{\mathrm{u}}}{\sigma_{\mathrm{s}}+\gamma H-\sigma_{\mathrm{t}}}
$$

Substituting Equations 6 and 7 into Equation 8, Equation 9 can be used to determine the FOS for known design parameters $\left(\sigma_{\mathrm{s}}, \sigma_{\mathrm{t}}, \gamma\right.$, $H, W$ and $S_{\mathrm{u}}$ ).

9.

$$
\mathrm{FOS}=\frac{N_{\mathrm{c}}}{N}=\frac{[ \pm 2 \cdot 51 \times \ln (H / W) \pm 2 \cdot 17] \times S_{\mathrm{u}}}{\sigma_{\mathrm{s}}+\gamma H-\sigma_{\mathrm{t}}}
$$

Equation 9 is also presented graphically in Figure 6. The design contour map of FOS was constructed based on the FDM numerical solutions.

By rearranging Equation 8, one can determine the required support pressure $\sigma_{\mathrm{t}}$ for a given FOS using the following equation

10.

$$
\sigma_{\mathrm{t}}=\sigma_{\mathrm{s}}+\gamma H-\left(\frac{N_{\mathrm{c}} \times S_{\mathrm{u}}}{\mathrm{FOS}}\right)
$$

\section{Comparison}

Figure 7 and Table 4 compare the $N_{\mathrm{c}}$ values obtained in this paper with those in the published literature. The comparison shows that the FDM results of $N_{\mathrm{c}}$ are considerably lower than the analytical upper-bound solutions of Davis (1968) for large $H / W$. Although Davis's investigation had been improved by Gunn (1980) by using the three rigid block parameters, the analytical upper-bound solutions of Gunn (1980) are still $4 \cdot 0-12 \cdot 9 \%$ larger than the current FDM.

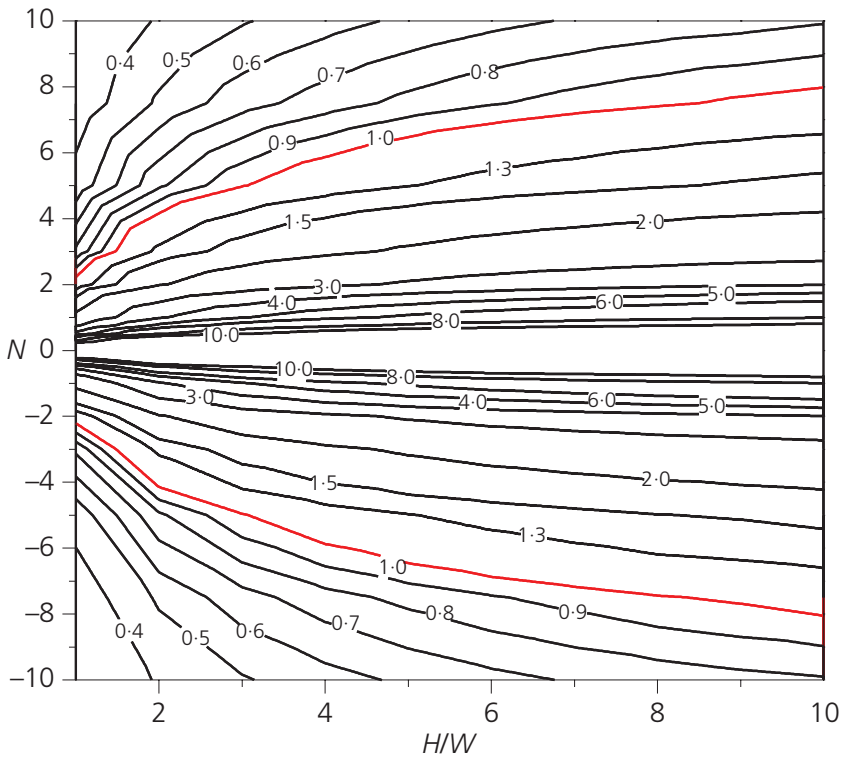

Figure 6. FOS design chart for various $N$ and $H / W$ values

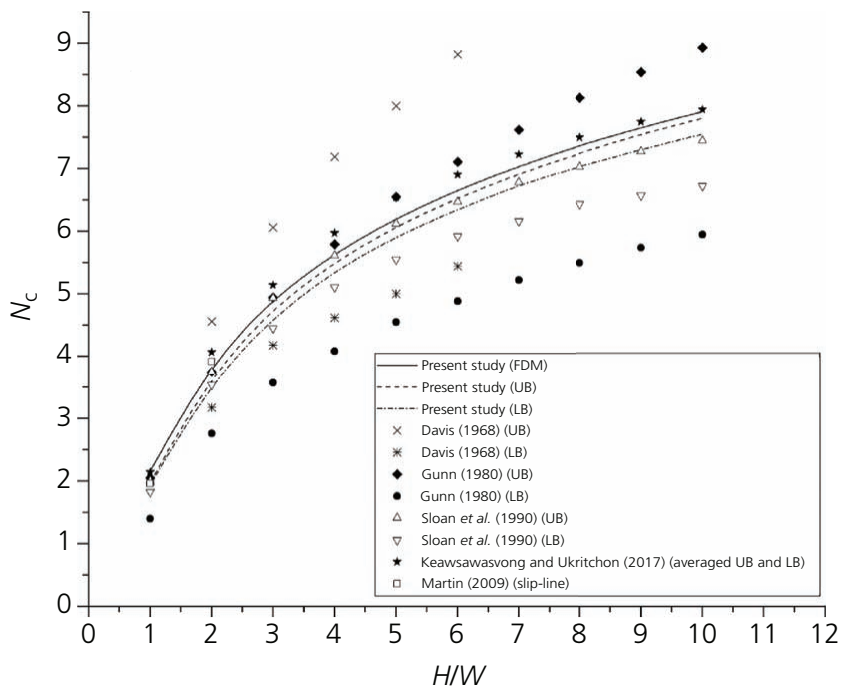

Figure 7. Comparison of $N_{c}$ values

The comparison in Figure 7 also shows some $0.65-15.00 \%$ difference between the FDM results and the results by Sloan et al. (1990) for the range of depth ratios $(H / W=1-10)$ studied. Although Sloan et al. (1990) carried out extensive research on trapdoor stability, the use of linear programming was a major drawback on the solution accuracy. In particular, the lower bound shows a large variation in comparison with FDM. The slip-line solutions of Martin (2009) were limited to shallow depth ratios up to $H / W=2$. Martin's results agree well with the current FDM solutions of $H / W=1$ and 2. Keawsawasvong and Ukritchon (2017) presented averaged upper- and lower-bound solutions for a 
Table 4. Comparison of $N_{c}$ values

\begin{tabular}{|c|c|c|c|c|c|c|c|c|c|c|c|}
\hline \multirow{2}{*}{$H / W$} & \multicolumn{3}{|c|}{ Present study } & \multicolumn{2}{|c|}{ Davis (1968) } & \multicolumn{2}{|c|}{ Gunn (1980) } & \multicolumn{2}{|c|}{ Sloan et al. (1990) } & \multirow{2}{*}{$\begin{array}{c}\text { Keawsawasvong and Ukritchon (2017) } \\
\text { Average (LB and UB) }\end{array}$} & \multirow{2}{*}{$\frac{\text { Martin (2009) }}{\text { Slip-line }}$} \\
\hline & FDM & LB & UB & LB & UB & LB & UB & LB & UB & & \\
\hline 1 & $2 \cdot 16$ & 1.94 & 1.98 & 2.00 & $2 \cdot 00$ & $1 \cdot 40$ & 2.05 & 1.83 & $2 \cdot 00$ & $2 \cdot 14$ & 1.96 \\
\hline 2 & 3.90 & $3 \cdot 59$ & $3 \cdot 71$ & $3 \cdot 17$ & $4 \cdot 56$ & $2 \cdot 76$ & 3.75 & $3 \cdot 54$ & $3 \cdot 75$ & $4 \cdot 07$ & 3.91 \\
\hline 3 & 4.93 & $4 \cdot 63$ & $4 \cdot 78$ & $4 \cdot 18$ & 6.06 & $3 \cdot 57$ & 4.94 & 4.45 & 4.93 & $5 \cdot 14$ & - \\
\hline 4 & $5 \cdot 65$ & $5 \cdot 37$ & $5 \cdot 51$ & $4 \cdot 62$ & $7 \cdot 19$ & $4 \cdot 08$ & $5 \cdot 79$ & $5 \cdot 11$ & $5 \cdot 61$ & $5 \cdot 97$ & - \\
\hline 5 & $6 \cdot 21$ & 5.92 & $6 \cdot 08$ & $5 \cdot 00$ & 8.00 & 4.55 & $6 \cdot 55$ & $5 \cdot 55$ & $6 \cdot 12$ & $6 \cdot 54$ & - \\
\hline 6 & $6 \cdot 66$ & $6 \cdot 35$ & 6.53 & $5 \cdot 44$ & 8.82 & 4.88 & $7 \cdot 11$ & 5.92 & $6 \cdot 47$ & 6.90 & - \\
\hline 7 & 7.04 & $6 \cdot 74$ & 6.92 & - & - & $5 \cdot 22$ & $7 \cdot 62$ & $6 \cdot 16$ & $6 \cdot 78$ & $7 \cdot 23$ & - \\
\hline 8 & $7 \cdot 37$ & 7.03 & $7 \cdot 25$ & - & - & $5 \cdot 49$ & $8 \cdot 13$ & $6 \cdot 43$ & $7 \cdot 02$ & $7 \cdot 50$ & - \\
\hline 9 & $7 \cdot 65$ & $7 \cdot 30$ & $7 \cdot 55$ & - & - & $5 \cdot 73$ & $8 \cdot 54$ & $6 \cdot 57$ & $7 \cdot 27$ & $7 \cdot 74$ & - \\
\hline 10 & 7.91 & $7 \cdot 55$ & $7 \cdot 80$ & - & - & $5 \cdot 94$ & 8.93 & $6 \cdot 72$ & $7 \cdot 44$ & $7 \cdot 94$ & - \\
\hline
\end{tabular}

wide range of depth ratios $(H / W)$ for homogeneous and nonhomogeneous clays. In general, their results of homogeneous clay agree well with the FDM results. Overall, the predicted trend of FDM results shows a good agreement with the FELA LB and UB solutions.

\section{Failure extent}

Results of the failure extent investigation are shown in Figure 8. The distance of failure extent was determined by inspection of the velocity vector plots produced in the program. Figure 8 suggests that the failure extent ratio $(E / W)$ is linearly proportional to the depth ratio $(H / W)$. The linear relationship is presented in the following equation

11. $\frac{E}{W}=1 \cdot 39\left(\frac{H}{W}\right)+0 \cdot 13$

A practical conclusion can be drawn from Table 5, showing that an approximately $55^{\circ}$ line can be drawn from the centre of the trapdoor to the outer boundary of the failure surface to estimate

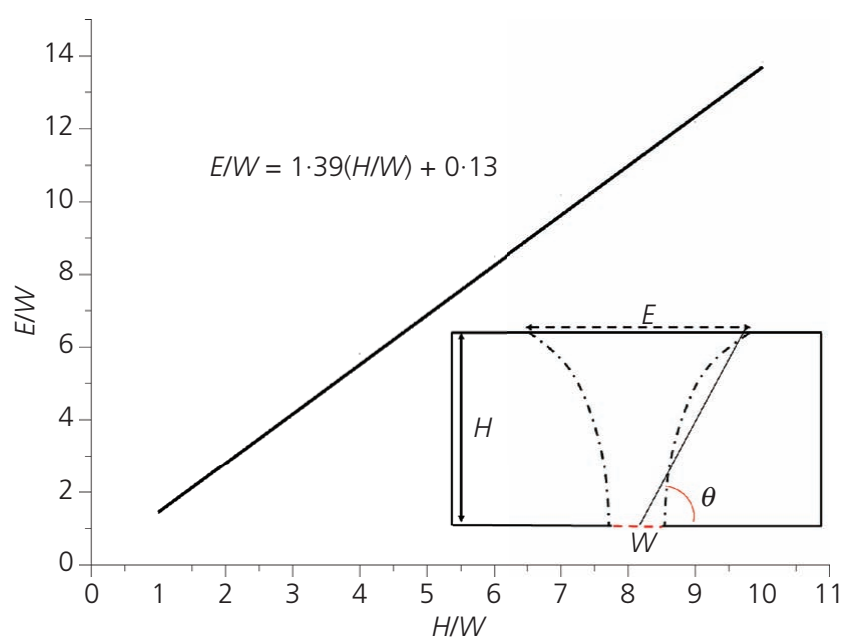

Figure 8. Failure extent the failure extent. Note that this investigation is valid for all values of stability numbers $(N)$.

\section{Work examples}

\section{Determine the FOS}

An old vertical mining shaft has no internal pressure and no surcharge pressure. For the given parameters $\left(S_{\mathrm{u}}=154 \mathrm{kPa}, \gamma=\right.$ $18 \mathrm{kN} / \mathrm{m}^{3}, H=36 \mathrm{~m}$ and $\left.W=6 \mathrm{~m}\right)$, determine the FOS.

- Since there is no internal pressure, only the collapse failure should be considered.

- The stability number is $N=\gamma H / S_{\mathrm{u}}=4 \cdot 21$.

- Using $H / W=6$ and $N=4 \cdot 21$, Equation 9 gives an FOS of $1 \cdot 58$ for the collapse.

- Using $H / W=6$ and $N=4 \cdot 21$, Figure 6 gives an approximate FOS of $1 \cdot 6$.

- An actual computer analysis of this case gives an FOS of 1.63.

What is the critical support pressure $\sigma_{\mathrm{t}}$ when $\mathrm{FOS}=1$ ?

- Using Equation $6, N_{\mathrm{c}}=3.45$ for collapse.

- From Equation 10, $\sigma_{\mathrm{t}}=\sigma_{\mathrm{s}}+\gamma H-\left(N_{\mathrm{c}} \times S_{\mathrm{u}} /\right.$ FOS $)=100+$ $(18 \times 10)-(3 \cdot 45 \times 30 / 1)=176 \cdot 5 \mathrm{kPa}$.

Table 5. Determination of failure extent

\begin{tabular}{|c|c|c|c|c|}
\hline $\begin{array}{l}\text { Depth } \\
\text { ratio, } \\
\text { H/W }\end{array}$ & $\begin{array}{c}\text { Actual } \\
\text { depth, } \\
\text { H: m }\end{array}$ & $\begin{array}{c}\text { Measured } \\
\text { surface half- } \\
\text { failure extent, } \\
\text { E/2: m }\end{array}$ & $\begin{array}{c}\text { Angle, } \theta= \\
\tan ^{-1} \\
{[H /(E / 2)]: \circ}\end{array}$ & $\begin{array}{c}\text { Ratio of } \\
\text { failure extent } \\
\text { to trapdoor } \\
\text { width, E/W }\end{array}$ \\
\hline 1 & 6 & $4 \cdot 50$ & $53 \cdot 1$ & 1.50 \\
\hline 2 & 12 & $8 \cdot 50$ & $54 \cdot 7$ & $2 \cdot 83$ \\
\hline 3 & 18 & $12 \cdot 5$ & $55 \cdot 2$ & $4 \cdot 17$ \\
\hline 4 & 24 & $17 \cdot 5$ & 53.9 & $5 \cdot 83$ \\
\hline 5 & 30 & $20 \cdot 5$ & 55.7 & 6.83 \\
\hline 6 & 36 & $25 \cdot 5$ & $54 \cdot 7$ & 8.50 \\
\hline 7 & 42 & $30 \cdot 5$ & $54 \cdot 0$ & $10 \cdot 17$ \\
\hline 8 & 48 & 35.0 & 53.9 & 11.67 \\
\hline 9 & 54 & $36 \cdot 5$ & 55.9 & $12 \cdot 17$ \\
\hline 10 & 60 & $41 \cdot 5$ & $55 \cdot 3$ & $13 \cdot 83$ \\
\hline
\end{tabular}

Half-cavity size $(W / 2)=3 \mathrm{~m}$ 
Estimate the depth of a sinkhole $(H)$

An existing sinkhole has a diameter of $10 \mathrm{~m}$. Estimate the depth of the sinkhole using the following parameters for cohesive soil: $S_{\mathrm{u}}=54 \mathrm{kPa}$ and $\gamma=19 \mathrm{kN} / \mathrm{m}^{3}$.

- Note that Equation 11 is independent of the design parameter $N$. The only needed information is $E$.

- From Equation $11,10 / W=1 \cdot 39 \times(H / W)+0 \cdot 13$.

- By ignoring the small value of $(0 \cdot 13 W)$, the depth $(H)$ is found to be $7 \cdot 19 \mathrm{~m}$.

\section{Design of a supported cavity $\left(\sigma_{t}\right)$}

An FOS of 4 is required for the design of an underground military bunker where the surcharge pressure is given as $\sigma_{\mathrm{s}}=50 \mathrm{kPa}$. The following parameters are known: $S_{\mathrm{u}}=25 \mathrm{kPa}, \gamma=18 \mathrm{kN} / \mathrm{m}^{3}, H=$ $40 \mathrm{~m}$ and $W=30 \mathrm{~m}$.

- Using Equation 6, the critical stability number is $N_{\mathrm{c}}=2 \cdot 89$. Note that Figure 5 can also be used to find the $N_{\mathrm{c}}$ value.

- Substitute the $N_{\mathrm{c}}$ value into Equation $10, \sigma_{\mathrm{t}}=\sigma_{\mathrm{s}}+\gamma H-\left(N_{\mathrm{c}} \times\right.$ $\left.S_{\mathrm{u}} / \mathrm{FOS}\right)=50+(18 \times 40)-(2 \cdot 9 \times 25 / 4)=752 \mathrm{kPa}$.

- The required pressure to support the cavity for an FOS of 4 is $752 \mathrm{kPa}$.

\section{Conclusion}

This study successfully investigated the stability of trapdoor problems using Broms and Bennermark's original stability number. Numerical results of this study were obtained by utilising the SSRM. Three numerical techniques were used - namely, the FDM, FELA UB and FELA LB.

The FOS was found to be a function of the depth ratio $(H / W)$ and stability number $(N)$. The numerical results suggest that the FOS increases when the stability number $(N)$ decreases. The FOS becomes very large when the stability $N$ is very small. Further investigation on failure mechanisms indicates a linear relationship between the failure extent ratio $(E / W)$ and the depth ratio $(H / W)$. The failure angle $(\theta)$ measured from the centre of the opening $(W)$ to the outer boundary of the failure surface is approximately equal to $55^{\circ}$ for all depth ratios $(H / W)$.

This investigation has improved the understanding of trapdoor stability and associated surface failure extent. Further study is needed for a more realistic three-dimensional analysis of sinkhole failure.

\section{REFERENCES}

Abdulla WA and Goodings DJ (1996) Modeling of sinkholes in weakly cemented sand. Journal of Geotechnical Engineering 122(12): 998-1005, https://doi.org/10.1061/(asce)0733-9410(1996)122:12(998).

Augarde CE, Lyamin AV and Sloan SW (2003) Prediction of undrained sinkhole collapse. Journal of Geotechnical and Geoenvironmental Engineering 129(3): 197-205, https://doi.org/10.1061/(ASCE)10900241(2003)129:3(197).

Broms BB and Bennermark H (1967) Stability of clay at vertical openings. Journal of Soil Mechanics and Foundations Division 93(1): 71-94.
Craig W (1990) Collapse of cohesive overburden following removal of support. Canadian Geotechnical Journal 27(3): 355-364, https://doi. org/10.1139/t90-046.

Davis E (1968) Theories of plasticity and the failure of soil masses. In Soil Mechanics Selected Topics (Lee IK (ed.)). Butterworths, London, UK, pp. 341-380

Davis E, Gunn M, Mair R and Seneviratine H (1980) The stability of shallow tunnels and underground openings in cohesive material. Géotechnique 30(4): 397-416, https://doi.org/10.1680/geot.1980.30.4.397.

Drumm EC, Aktürk Ö, Akgün H and Tutluoğlu L (2009) Stability charts for the collapse of residual soil in karst. Journal of Geotechnical and Geoenvironmental Engineering 135(7): 925-931, https://doi.org/10. 1061/(ASCE)GT.1943-5606.0000066.

Griffiths D and Lane P (1999) Slope stability analysis by finite elements. Géotechnique 49(3): 387-403, https://doi.org/10.1680/geot.1999.49.3. 387.

Gunn M (1980) Limit analysis of undrained stability problems using a very small computer. Proceedings of the Symposium on Computer Applications to Geotechnical Problems in Highway Engineering, Cambridge, UK, pp. 5-30.

Itasca (2003) Fast Lagrangian Analysis of Continua, Version 4.0. Itasca Consulting Group, Minneapolis, MN, USA.

Jacobsz SW (2016) Trapdoor experiments studying cavity propagation. In Proceedings of the First Southern African Geotechnical Conference (Jacobsz SW (ed.)). CRC Press, Boca Raton, FL, USA, pp. 159-165.

Keawsawasvong S and Ukritchon B (2017) Undrained stability of an active planar trapdoor in non-homogeneous clays with a linear increase of strength with depth. Computers and Geotechnics 81: 284-293, https://doi.org/10.1016/j.compgeo.2016.08.027.

Koutsabeloulis N and Griffiths D (1989) Numerical modelling of the trap door problem. Géotechnique 39(1): 77-89, https://doi.org/10.1680/ geot.1989.39.1.77.

Krabbenhoft K and Lyamin AV (2015) Strength reduction finite-element limit analysis. Géotechnique Letters 5(4): 250-253, https://doi.org/10. 1680/jgele.15.00110.

Lyamin A and Sloan S (2002a) Lower bound limit analysis using nonlinear programming. International Journal for Numerical Methods in Engineering 55(5): 573-611, https://doi.org/10.1002/nme.511.

Lyamin AV and Sloan S (2002b) Upper bound limit analysis using linear finite elements and non-linear programming. International Journal for Numerical and Analytical Methods in Geomechanics 26(2): 181-216, https://doi.org/10.1002/nag.198.

Martin C (2009) Undrained collapse of a shallow plane-strain trapdoor. Géotechnique 59(10): 855-863, https://doi.org/10.1680/geot.8.T.023.

Matsui T and San KC (1992) Finite element slope stability analysis by shear strength reduction technique. Soils and Foundations 32(1): 59-70, https://doi.org/10.3208/sandf1972.32.59.

Michalowski RL (2002) Stability charts for uniform slopes. Journal of Geotechnical and Geoenvironmental Engineering 128(4): 351-355, https://doi.org/10.1061/(ASCE)1090-0241(2002)128:4(351).

Newton J (1976) Induced sinkholes-a continuing problem along Alabama highways. In Land Subsidence Symposium: Proceedings of the Second International Symposium on Land Subsidence, held at Anaheim, California, 13-17 December 1976. International Association of Hydrological Sciences (IAHS), Wallingford, UK, publication no. 121, pp. 453-463.

Shiau J and Al-Asadi F (2018) Revisiting Broms and Bennermarks' original stability number for tunnel headings. Géotechnique Letters 8(4): 310-315, https://doi.org/10.1680/jgele.18.00145.

Shiau JS and Sams MS (2019) Relating volume loss and Greenfield settlement. Tunnelling and Underground Space Technology 83: 145-152, https://doi.org/10.1016/j.tust.2018.09.041.

Shiau J, Lamb B, Sams M and Lobwein J (2017) Stability charts for unsupported circular tunnels in cohesive soils. International Journal of GEOMATE 13(39): 95-102, https://doi.org/10.21660/2017.39.47674. 
Shiau J, Al-Asadi F and Hassan MM (2018) Stability charts for unsupported plane strain tunnel headings in homogeneous undrained clay. International Journal of GEOMATE 14(41): 19-26, https://doi. org/10.21660/20178.41.29138.

Sloan SW (2013) Geotechnical stability analysis. Géotechnique 63(7): 531-571, https://doi.org/10.1680/geot.12.RL.001.

Sloan S, Assadi A and Purushothaman N (1990) Undrained stability of a trapdoor. Géotechnique 40(1): 45-62, https://doi.org/10.1680/geot. 1990.40.1.45.

Sowers GF (1996) Building on Sinkholes: Design and Construction of Foundations in Karst Terrain. American Society of Civil Engineers, New York, NY, USA.

Terzaghi K (1936) Stress distribution in dry and saturated sand above a yielding trap-door. In Proceedings of the International Conference of Soil Mechanics and Foundation Engineering.
Harvard University Press, Cambridge, MA, USA, vol. 1, no. 4 pp. 307-311.

Tharp TM (2003) Cover-collapse sinkhole formation and soil plasticity. Proceedings of the Ninth Multidisciplinary Conference on Sinkholes and the Engineering and Environmental Impacts of Karst, Huntsville, AL, USA, pp. 110-123.

Ugai K and Leshchinsky D (1995) Three-dimensional limit equilibrium and finite element analyses: a comparison of results. Soils and Foundations 35(4): 1-7, https://doi.org/10.3208/sandf.35.4_1.

Yang MZ and Drumm EC (2002) Stability evaluation for the siting of municipal landfills in karst. Engineering Geology 65(2): 185-195, https://doi.org/10.1016/S0013-7952(01)00128-4.

Zienkiewicz O, Humpheson C and Lewis R (1975) Associated and non-associated visco-plasticity and plasticity in soil mechanics. Géotechnique 25(4): 671-689, https://doi.org/10.1680/geot.1975.25.4.671.

\section{How can you contribute?}

To discuss this paper, please submit up to 500 words to the editor at journals@ice.org.uk. Your contribution will be forwarded to the author(s) for a reply and, if considered appropriate by the editorial board, it will be published as a discussion in a future issue of the journal. 